\title{
Estrangulamento herniario
}

\author{
Caso apresentado á Sociedade Arnaldo \\ Vieira de Carvalho pelo doutorando \\ Dario Augusto de Carvalho Franco.
}

\begin{abstract}
GENTILEZA de um convite, envolvendo honroso conceito para o simples autor deste trabalho, animou-nos a expôr-vos algumas considerações sobre o estrangulamento herniario e suas complicações.

Em se tratando dum assumpto assáz debatido, e por demais conhecido, é bem de ver que nada de novo pretendemos trazer perante vós.

Comtudo, varios factores concorreram para que o presente caso se tornasse, de algum modo, interessante: a longaminidade do estrangulamento; o processo operatorio; o tratamento post-operatorio afinal.

Assim sendo, faremos com traços os mais breves que estiverem ao nosso alcance, algumas considerações geraes sobre este capitulo da pathologia cirurgica, passando em seguida á leitura da observação, que deu ensejo a esta communicação.

Uma hernia é estrangulada, quando a viscera, ou as visceras, nella contidas, soffrem uma constricção brusca, impedindo a sua reducção, acarretando perturbações de ordem local e geral, as quaes traduzem os phenomenos pathologicos que nella se passam.

Da propria definição se infere, que a maior ou menor gravidade do estrangulamento depende da viscera contida, e do gráo de constricção.

Todas as visceras, salvo o pancreas, têm sido encontradas nos saccos herniarios; porém, sendo o epiplo e o intestino delgado os mais frequentemente encontrados, somente delles nos occuparemos.

A constricção completa do intestino nos revela o quadro clinico da obstrucção; uma hernia de pinçamento lateral, define a constricção incompleta desse -mesmo orgão.

$\mathrm{O}$ epiplo tambem se estrangula com muita frequencia, quer ao mesmo tempo que o intestino, quer isoladamente. Comprehendemos a difficuldade de um diagnostico differencial entre uma hernia com pinçamento lateral e um estrangulamento epiploico, sem importancia de resto na pratica, porquanto, um cirurgião nunca espera o appare-
\end{abstract}


cimento de symptomas alarmantes, informadores da viscera estrangulada, para depois operar o seu doente.

Os antigos conheciam bem o estrangulamento, mas o attribuiam a causas diversas, no meio das quaes dominava sobretudo o "engasgamento", consecutivo ao accumulo de fézes na alça herniada.

Foi Riolan quem definiu bem o estrangulamento, depois da descoberta por parte deste cirurgião, dos anneis herniarios.

Porém, sobre o mecanismo do estrangulamento, levantaram-se numerosas discussões: Richter incriminava o annel; Scarpa attribuia a uma torsão da alça; Malgaigne responsabilisava a peritonite herniaria.

Saviard, Arnaud e Ledran, observando a persistencia de estrangulamentos, não obstante o debridamento do annel, concluiram ser 0 colo do sacco o agente da constricção.

$\mathrm{Na}$ pratica essas ethio-pathogenias multiplas, essas distincções subtis, nos interessam pouco, pois todo estrangulamento, qualquer que seja a sua causa, nos deverá sempre levar a uma intervenção cirurgica. Concluimos assim dizendo que existem hernias nas quaes o colo é o agente de estrangulamento, noutras é o annel, o responsavel pela constricção.

Uma vez verificado o estrangulamento, quaes os processos anatomo-pathologicos observados, decorrentes dessa constriç̧ão ?

Consideraremos as modificações que se passam respectivamente no continente e no conteúdo herniarios. Os envolucros externos são, na maioria das vezes, pouco modificados. Raros são os casos em que a pelle se torna avermelhada, em que existem signaes phleimonosos, ou então se forma um anus artificial.

O sacco, quasi sempre, apresenta-se espessado, adherente ao conteúdo, ou o mais das vezes separado deste por certa quantidade de liquido citrino, sanguinolento, ou fecaloide.

No conteúdo herniario, os accidentes vasculares são os predominantes; perturbações circulatorias e lesões ischemicas, resultantes da constriç̧ão soffrida pela parte estrangulada. E' de maximo interesse pratico o conhecimento dessas lesões, pois serão ellas que dictarão a conducta operatoria.

$\mathrm{Na}$ alça estrangulada, se dá em primeiro lugar uma phase de congestão; ás veias, de parede menos resistentes, soffrem logo as consequencias da compressão. Dahi a estase venosa, com coloração vinhosa da alça e formação de fócos hemorrhagicos. Durante a estagnação venosa, as arterias continuam, ainda vehiculando o sangue; resulta uma transudação atravez da parede intestinal e accumulo de liquido no sacco herniario.

Seguem-se, depois, lesões ischemicas e infecciosas. Dá-se a producção de um sulco ao nivel da compressão, delgado e de côr acinzentada. Produzem-se lesões do corpo da alça, devido á migração mi- 
crobiana atravez da parede intestinal. Dahi a peritonite herniaria, com tendencia á generalisação.

Nesse estado, durante a herniotomia, é particularmente difficil indicarmos qual a sorte da alça estrangulada. Muitas vezes de quasi negra que era, com o reaquecimento pelo soro, tende a voltar sua coloração normal. Reduz-se e pratica-se a cura radical.

Noutras, notamos algumas zonas ecchymoticas, apenas. Reduzimos a alça, e em breve teremos uma infecção peritonial mortal.

Desconfiae dessas ecchymoses: são determinadas por processos trombo-embolicos que proseguirão na alça reduzida.

Em uma phase mais adeantada temos a necrose, o esphacelo. As placas necroticas apresentam-se acinzentadas, são muito friaveis, rompem-se facilmente.

O diagnostico da hernia estrangulada é relativamente facil. Quasi sempre o doente refere ter "descido" a sua hernia e as manobras costumeiras para reduzil-a foram improficuas.

Irreductibilidade brusca, dôr, nauseas, são os primeiros symptomas que apparecem. Seguem-se depois os vomitos, alimentares a principio, para se tornarem mucosos, biliares e fecaloides por ultimo. Installa-se o quadro da oclusão, o estado geral se altera a peritonite se declara levando fatalmente o organismo á ruina.

Ha dois erros a evitar: acreditarmos em uma hernia que não existe, ou, peior ainda, não vermos uma hernia que existe. $\mathrm{O}$ resto parece-nos não apresentar difficuldades.

Procurar diagnosticar a forma da obstrucção, ou o estado em que já se acha a viscera, seria superfluo, porquanto, desde que seja feito um diagnostico de hernia estrangulada, a sua reducção se impõe.

A reducção deve ser operatoria: toda hernia estrangulada requer kelotomia immediata. A manobra do taxis, deve assim passar para a ordem dos factos historicos.

Incisar as partes molles; atravessar os planos anatomicos; chegar ao sacco; isolal-o; abril-o; seccionar o agente de constricção, é tudo obra de um momento.

- Segue-se após o tempo mais delicado e importante da operação; o exame do conteúdo herniario.

O intestino será tratado pelo soro quente. A alça não apresenta nenhuma solução de continuidade, tende a tomar sua côr natural depois de aquecida; reduzimos e praticamos a cura radical.

Existem algumas placas de gangrena: invaginamos e reduzimos em seguida. Si a gangrena occupar uma superficie muito grande, se a alça não melhorar sua coloração, devemos praticar a enterectomia, seguida de enterorrhaphia immediata. O mesmo procedimento devemos ter com a gangrena perfurante.

Neste particular é necessario conhecermos as opiniões dos diversos auctores. 
Verneuil achava que a ressecção seguida de sutura era horrivelmente grave, ao passo que o estabelecimento de um anus artificial era relativamente benigno.

Trélat só admittia o anus artificial, quando elle se estabelecia por si mesmo.

$\mathrm{Na}$ gangrena perfurante, Marion aconselha a pratica do anus artificial.

Lejars faz sentir os inconvenientes do anus artificial, por obrigar o paciente a uma nova intervenção, a qual não está isenta de perigo.

Czerny, Hahn, Hocher e outros reuniram cento e dezoito observações de herniotomias, em cincoenta e uma das quaes, foi applicado o annus contra a natureza, tendo sido feita em sessenta e sete a ressecção seguida de anastomose.

Para o primeiro processo, tiveram esses autores uma porcentagem de $76 \%$ de mortes, ao passo que para o segundo processo, tiveram uma porcentagem de $46 \%$ de mortes, demonstrando assim as vantagens da anastomose.

Esta é, segundo Gosset, a operação de escolha; o anus artificial tira as suas indicações, das contra-indicações daquella.

A ressecção intestinal é simples: retiramos para fóra da cavidade a alça que se quer ressecar, isolando-a por meio de campos esterilizados.

Por expressão esvasiamol-a do seu conteúdo. Collocamos duas pinças copro-estaticas, além dos pontos a seccionar, e duas pinças de Kocher nas extremidades do segmento sacrificado.

Seccionamos o intestino rente ás pinças de Kocher e ressecamos a cunha mesenterica, um pouco menor do que a ressecção intestinal.

Praticamos a hemostase com cat-gut.

Kocher recommenda a conservação do mesenterio intersegmentario, sempre que este não estiver compromettido. Evita assim a ressecção em cunha, para maior garantia da irrigação intestinal. A hemostase será feita no bordo seccionado.

A anastomose, de technica mais delicada, já exige por parte do operador, uma certa destreza. Começamos por encontrar difficuldades na escolha do fio: muitos cirurgiões empregam seda ou linho; com o fito de obterem maior segurança na sutura. Si considerarmos os inconvenientes da implantação dum fio inabsorvivel, em um meio septico como o intestinal, abandonaremos immediatamente o emprego delles.

O fio de escolha será portanto o cat-gut, de preferencia o chromado, pois a cicatrização intestinal, sendo muito rapida, não ha necessidade da permanencia dum fio, na sutura, por um tempo muito longo.

Rapida, hemostatica, estanque e isolante, são as quatro principaes condições exigidas para obtenção duma boa sutura intestinal. 
E' a sutura continua, de pontos bem aproximados, que melhor satisfaz taes exigencias. Como restabelecer a continuidade intestinal por meio desta sutura? E' classico effectual-a em dois planos: um total perfurante, comprehendendo as tres tunicas intestinaes, outra não perfurante, comprehendendo somente a serosa, servindo para recobrir, protegendo a primeira sutura.

Cunéo e de Martel, em discussões varias, na Sociedade de Cirurgia de Pariz, demonstraram que essa sutura assim praticada, não offerecia muita garantia, podendo romper-se com uma pressão um pouco mais elevada do conteúdo intestinal.

Além disso, de Martel, insiste na formação de um espaço morto, entre as duas series de suturas, forçosamente um pouco afastadas, no qual vem ter o conteúdo intestinal, seguindo os fios perfurantes da sutura total.

A sutura commumente praticada, a que offerece maiores commodidades ao operador, a mais facil portanto, apresenta os inconvenientes apontados por Cunéo e de Martel.

Consiste aquella em perfurar serosa, muscular, mucosa, de um lado; mucosa, muscular, serosa, do outro. Ella effectua um adossamento muco-mucoso e a mucosa exhuberante ficará encerrada em uma cavidade fechada, determinada por uma segunda sutura.

Para conseguir a inversão da mucosa, Connel Mayo, von Schmoden, Cunéo, etc. idéaram pontos, na verdade muito engenhosos, mas de difficil pratica e passiveis tambem de critica.

Dois processos merecedores duma especial attenção, devido não só á simplicidade da technica, como tambem á realização das condições duma boa sutura, são incontestavelmente o de Toupet e o de Robineau, do Hospital Necker.

Consiste o primeiro em collocar tres pontos de apoio nas extremidades a anastomosar e em seguida effectuar a sutura perfurante na ordem inversa da geralmente empregada, isto é, começar na luz do intestino, suturando mucosa, muscular, serosa, de um lado; serosa, muscular, mucosa, do outro. O ponto fraco mesenterico é reforçado pelo artificio do retorno.

$\mathrm{Na}$ technica de Robineau a regra da conservação dos dois planos é obedecida, mas este cirurgião sutura num primeiro plano, somente a mucosa, recobrindo-a em seguida com uma segunda sutura seromusculosa.

Quanto ao processo anastomotico a ser empregado, depende essencialmente das condições operatorias.

Tres são as maneiras de anastomosar o intestino: anastomose termino-terminal, latero-lateral e termino-lateral.

A maioria dos cirurgiões está de accôrdo em que a anastomose latero-lateral reúne condições mais favoraveis, que qualquer outra, para obtermos um bom resultado operatorio. 
Afastar o inconveniente do ponto fraco mesenterico, não produzir estenose no tubo digestivo, estar livre de ser forçada pelo conteúdo intestinal, são as principaes vantagens que a levara ao acolhimento verdadeiramente enthusiastico, confiante e rapido, por parte das maiores autoridades na materia.

Para effectual-a é necessario:

$\left.1 .^{\circ}\right)$ secção perpendicular á luz, como ou sem esmagadores. Fe. chamento das duas extremidades; este será mais rapido si a secção foi feita com esmagadores; uma ligadura da superficie esmagada e um fio em bolsa, são sufficientes.

$2 .^{\circ}$ ) reunião dos dois segmentos a anastomosar. Elles deverão ser collocados no sentido do peristaltismo, e não em "cano de espingarda" como manda a maioria dos autores.

3. ) confecção da bocca. Ella será longa e terminará perto dos fundos do sacco.

Deante das vantagens apresentadas pela anastomose laterolateral, parece-nos á primeira vista que seja ella a mais empregada no restabelecimento da continuidade intestinal.

Não é assim, no entretanto, porque ao par das suas boas qualidades, ella apresenta tambem desvantagens, dentre as quaes mencionaremos a sua technica mais difficil e de pratica mais morosa, argumentos sufficientemente poderosos para evitarem a sua pratica corrente.

E' a anastomose termino-terminal a mais facil e rapida. Ella tem ainda a seu favor ser a mais physiologica, porque restabelece o mais perto do natural a continuidade do tubo digestivo. Bem effectuada, ella não teme os inconvenientes do ponto fraco mesenterico, nem do estreitamento intestinal: o ponto fraco mesenterico será reforçado pela manobra de Toupet; a estenose, será evitada pela technica de Lockhart-Mummery. Será portanto esse o processo de escolha, e as outras anastomoses serão feitas, quando exsitirem contra-indicações formaes para o estabelecimento duma anastomose termino-terminal.

Quanto á anastomose termino-lateral, as suas indicações se resumem, quasi exclusivamente, ás implantações ileo-colicas.

A cura da hernia estrangulada depende principalmente do tempo de estrangulamento.

E' o que podemos verificar pelos dados estatisticos do Prof. Henggeler, de Philadelphia, o qual, de mil quatrocentas e vinte e nove herniotomias por estrangulamento, observou as seguintes porcentagens de exito lethal:

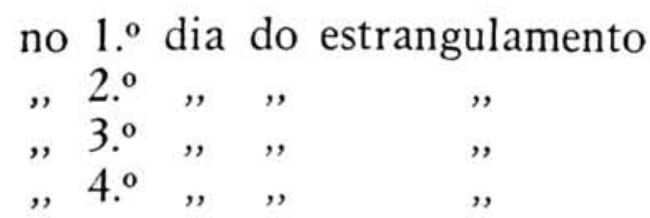

$8 \%$ de mortes

$22 \%$, ,

$45 \%,$,

$60 \%, "$, 
A observação que agora passaremos a ler, vem demonstrar a vantagem de não ser o cirurgião escolastico e sim resolver no momento, de conformidade com as necessidades do paciente, o qual deposita confiante a propria vida em suas mã̃os. $\mathrm{O}$ cirurgião deve ser ecletico, nunca operar com uma conducta preconcebida, estabelecendo de ante-mão qual vai ser a sua acção.

Como podereis ajuizar, daqui ha um momento, em um caso como este, attendido pelo medico interno da Santa Casa, no dia 7 de março do corrente anno, a conselho de grande numero de autores, elle deveria praticar um anus "practer naturalis" o qual segundo o proprio Lejars não está isento de serios inconvenientes. $\mathrm{O}$ paciente teria que se submetter a uma nova intervenção, e talvez não chegasse ao resultado desejado.

A cura obtida dependeu, em grande parte, do methodo operatorio, radical e definitivo, como ides ouvir pela leitura da presente observação:

M. P., brasileiro, lavrador, pardo, 49 annos de idade, casado.

ANAMNÉSE: a) antecedentes bereditarios: Paes fallecidos por causa ignorada pelo paciente. Possuia um irmão e uma irmã - o primeiro foi assassinado aos 22 annos de idade e a segunda foi victimada pelo impaludismo.

b) Antecedentes pessoaes: Gonorrhéa aos 14 annos de idade. Sarampo, coqueluche e varicela aos 18. Impaludismo aos 30. Pneumonia aos 40. Bronchite chronica ha muitos annos que o ataca de quando em vez. Fuma e bebe pouco.

MOLESTIA ACTUAL: Refere o paciente que ha dois mezes levou uma queda, ficando com o corpo "em falso" - sentia no momento uma pequena dôr na região inguinal direita e notou o apparecimento de um pequeno tumor na mesma região.

Posteriormente o referido tumor foi augmentando gradativamente com os esforços feitos pelo paciente em sua labuta diaria.

Ha oito dias, repentinamente, o tumor já de proporções bem maiores, deixou de se reduzir, cessando concomitantemente as funcções intestinaes do paciente.

Sentindo-se muito mal, vomitando tudo quanto ingeria, e peiorando continuamente, procurou afinal um facultativo do lugar, o qual o aconselhou a vir immediatamente para São Paulo, ingressando na Santa Casa, trazido pela Assistencia, ás 14 horas e 45 minutos, com fortes dores no ventre, principalmente na região inguino-abdominal direita, ancias de vomito intensas, obstrucção intestinal completa e voz apagada.

EXAME GERAL: Individuo emmagrecido. Segmento cephalico e membros normaes. O paciente apresenta facies afilada, francamente peritoneal, grande defesa da parede abdominal e muita sensibilidade 
á palpação da mesma. O exame dos differentes apparelhos nada digno de nota revelou. Temperatura axillar: $36^{\circ}$. Pulso: 120 .

EXAḾE LOCAL: $A^{\prime}$ inspecção se nota, na região inguinal direita do paciente, a presença de um tumor alongado, medindo uns dez centimetros de comprimento por cinco de largura. A' palpação se verifica que é de consistencia molle, accusando o paciente grande sensibilidade. Não foi tentada a reducção do tumor.

DIAGNOSTICo: Hernia inguinal estrangulada ha oito dias.

OPERAÇÃo: Kelotomia. Resecção intestinal. Entero-anastomose termino-terminal.

Operador: Dr. Oscar I. A. Bruno. Auxiliar: Doutorando Dario de Carvalho Franco. Data: 7-3-27. Inicio: 15 horas. Fim: 15 horas e 57 minutos. Duração: 57 minutos.

Anesthesia: Geral. Ether ethylico. Accidentes na anesthesia: Não houve. Accidentes na operação: Não houve. Suturas profundas: A cat-gut. Suturas superficiaes: Crina de Florença e agrafes Michel. Drenagem: Tubular.

\section{DESCRIPÇ Ã O D A OPERAÇÃ O}

Desinfecção e protecção do campo operatorio. Incisão da pelle sobre o grande eixo do tumor numa extensão de dez centimetros. Collocam-se campos esterilizados protegendo os labios da ferida cutanea. Exposta a aponevrose do musculo grande obliquo do abdomen e encontrado o annel inguinal externo secciona-se o referido annel e prolonga-se a incisão sobre a aponevrose numa extensão de cinco centimetros. Abaixo da aponevrose do grande obliquo e um pouco acima do annel inguinal externo encontra-se um annel fibroso que tambem é seccionado após o isolamento do tumor herniario dos tecidos circumvisinhos e proteç̧ão dos mesmos com novos campos esterilizados.

Effectua-se em seguida a abertura do sacco herniario (que se acha bastante espessado e infiltrado) dando-se o escoamento de regular quantidade de liquido amarellado e fétido o qual é estancado immediatamente; substituem-se os campos esterilizados - verifica-se que o conteúdo da hernia é constituido por uma alça intestinal delgada, com o seu respectivo meso, achando-se ella gangrenada e apresentando duas perfurações na sua extremidade distal: uma das perfurações medía mais ou menos um centimetro quadrado e a outra meio centimetro quadrado.

Após apprehensão da alça intestinal com uma compressa esterilizada o operador com o dedo indicador direito verifica a presença profundamente, de um novo annel fibroso correspondente ao "collet" da hernia e que era a causa do estrangulamento - exteriorizado esse 
annel é elle seccionado com a tesoura sobre o dedo indicador esquerdo prolongando-se a secção peritonel, numa extensão de trez centimetros.

Como as duas extremidades intestinaes não faziam receiar um futuro estenose devido ao calibre que apresentavam o qual tambem era identico nas duas e para se ganhar tempo foi praticada a enteroanastomose termino-terminal realisando-se primeiro uma sutura total com cat-gut $n .^{\circ} 1$ (tomando-se cuidado para que a mucosa intestinal ficasse invertida, em toda circumferencia do orgão, para dentro do lume da viscera) e depois outra sero-serosa com cat-gut n. ${ }^{\circ}$ 0. Colloca-se um ponto de reforço no ponto mesenterico e outro no bordo livre. Terminada a entero-anastomose o intestino é lavado com ether ethylico - o operador e o auxiliar desinfectam as luvas.

Em seguida isolam-se os elementos do cordão do sacco herniario e realiza-se a extirpação deste.

Pratica-se depois o methodo de Solieri nos casos de contaminação peritoneal introduzindo-se dez centimetros cubicos de épargol na cavidade peritoneal (na falta de electrargol que é o preparado de prata colloidal aconselhado pelo referido autor).

Colloca-se um dreno de borracha, de grosso calibre, no angulo inferior da incisão drenando a cavidade abdominal e approximam-se os labios da ferida operatoria com um ponto de crina de Florença e alguns agrafes de Michel.

Curativo: - Bolsa de gelo sobre o ventre.

\section{PERIODO POST-OPERATORIO}

7-3-27 - Logo após á intervenção foram injectados dez centimetros cubicos de oleo camphorado e dois de cafeina e um litro de sôro physiologico via sub-cutanea. $\mathrm{O}$ paciente não teve vomitos e nem nauseas.

8-3-27 - De manhã: Temperatura axillar: $36^{\circ}, 5$ - Pulso: 62 . $\mathrm{O}$ paciente se acha com o ventre flacido e não accusa nauseas. Ao se renovar o curativo move-se o dreno e introduz-se cinco centimetros cubicos de épargol no seu interior. Injectam-se outros cinco centimetros cubicos do mesmo preparado na cavidade peritoneal, segundo a technica aconselhada por Solieri, introduzindo-se a agulha a dois centimetros para dentro e para cima da espinha illiaca antero-super esquerda após fazer o doente permanecer em decubito lateral direito. Injecção de dois litros de sôro physiologico nas 24 horas. Bolsa de gelo sobre o ventre.

9-3-27 - De manhã: Temperatura axillar: 366. Pulso: 66.

Ventre flacido. Renovando-se o curativo corta-se um pedaço do dreno e introduz-se nelle cinco centimetros cubicos de épargol. In- 
jecção de outros cinco centimetros cubicos do mesmo medicamento na cavidade peritoneal segundo a technica acima descripta. Dois litros de sôro physiologico pela via hypodermica nas 24 horas, como na vespera. Gelo sobre o ventre.

10-3-27 - De manhã: Temperatura axillar: 360,5 - Pulso: 68 .

Ventre flacido. Ao se fazer a renovação do curativo corta-se nova porção do dreno e derrama-se cinco centimetros cubicos de épargol no seu interior. Dois litros de sôro physiologico nas 24 horas. O paciente refere que nesta data expelliu, espontaneamente, fezes intestinaes. Bolsa de gelo sobre o ventre.

11-3-27 — De manhã: Temperatura axillar: $36^{\circ}, 4-$ Pulso: 66.

Ventre flacido. Renova-se o curativo, diminue-se o dreno e introduz-se cinco centimetros cubicos de épargol no mesmo. Bolsa de gelo sobre o ventre.

12-3-27 - De manhã: Temperatura axillar: $36^{\circ}, 4$ - Pulso: 64 .

Retira-se o dreno.

13-3-27 — De manhã: Temperatura axillar: $36^{\circ}, 4-$ Pulso: 68.

Curativo. O paciente informa que teve nesta data uma pequena evacuação liquida, espontaneamente.

Do dia 14-3-27 ao dia 30-3-27 inclusive, data em que o paciente teve alta, curado, ha a registar somente que o curativo foi renovado diariamente; a quantidade de alimentos ingerida pelo paciente foi augmentada gradativamente, tendo o paciente começado a levantar-se do leito no decimo dia.

N. B. - A tarde a temperatura do paciente oscillou sempre ao redor de $36^{\circ}, 5$ e o pulso em torno de 66 pulsações por minuto.

O épargol foi applicado pela primeira vez na Santa Casa, e provavelmente em São Paulo, pelo Dr. Oscar Bruno, em 28 de Fevereiro do corrente anno, num caso de peritonite appendicular.

Antes da intervenção o paciente apresentava $39^{\circ}, 5$ de temperatura axillar e 100 pulsações por minuto.

No dia seguinte, $1 .^{\circ}$ de março, a temperatura cahiu para $37^{\circ}$ e o pulso a 56. Nas dias subsequentes observamos a temperatura e o pulso do doente que foram os seguintes:

\begin{tabular}{|c|c|c|c|}
\hline $2-3-27-$ & Temperatura: & $36^{\circ}$ & Pulso: \\
\hline $3-3-27-$ & $"$ & $36^{\circ}$ & ", \\
\hline $4-3-27-$ & , & $36^{\circ}, 2$ & , \\
\hline$-3-27-$ & , & $36^{\circ}, 2$ & ,, \\
\hline$-3-27-$ & , & $36^{\circ}, 4$ & , \\
\hline
\end{tabular}


No dia 6 de Março o doente foi removido para outro Hospital, em boas condições.

A segunda vez foi o épargol applicado no caso da hernia estrangulada.

Verificamos nos dois casos a reducção para metade, das pulsações por minuto.

Este facto nos leva a crer, ter a prata colloidal uma determinada acção sobre o musculo cardiaco, ou sobre os centros cardiovasculares, além das suas propriedades microbicidas e talvez tambem da sua intervenção estimulante sobre a phagocytose, como refere René Mosti em seu artigo inserto nos Annaes dos Laboratorios Clin.

E' o que nos será revelado pelos estudos que estão sendo effectuados nesse sentido.

\section{PHARMACIA LANGE}

PREÇOS ESPECIAES PARA MEDICOS E ESTUDANTES DE MEDICINA.

Pedidos por Telephone - Central 2223 RUA VERGUEIRO, 10 - S. PAULO 